BMJ Open Diabetes Research $\&$ Care

\title{
Optical coherence tomography: a novel imaging approach to visualize and quantify cutaneous microvascular structure and function in patients with diabetes
}

\author{
Raden Argarini, ${ }^{1,2}$ Robert A McLaughlin (D) , ${ }^{3,4}$ Simon Z Joseph, ${ }^{5}$ Louise H Naylor, ${ }^{2}$ \\ Howard H Carter, ${ }^{2}$ Bu B Yeap, ${ }^{6,7}$ Shirley J Jansen, ${ }^{5,8}$ Daniel J Green (1) ${ }^{2}$
}

To cite: Argarini $R$, McLaughlin RA, Joseph SZ, et al. Optical coherence tomography: a novel imaging approach to visualize and quantify cutaneous microvascular structure and function in patients with diabetes. BMJ Open Diab Res Care 2020;8:e001479. doi:10.1136/ bmjdrc-2020-001479

Received 22 April 2020 Revised 5 June 2020 Accepted 27 June 2020
Check for updates

(c) Author(s) (or their employer(s)) 2020. Re-use permitted under CC BY-NC. No commercial re-use. See rights and permissions. Published by BMJ.

For numbered affiliations see end of article.

Correspondence to Dr Daniel J Green; danny.green@uwa.edu.au

\section{ABSTRACT}

Introduction The pathophysiology of microvascular disease is poorly understood, partly due to the lack of tools to directly image microvessels in vivo.

Research design and methods In this study, we deployed a novel optical coherence tomography (OCT) technique during local skin heating to assess microvascular structure and function in diabetics with (DFU group, $n=13$ ) and without (DNU group, $n=10$ ) foot ulceration, and healthy controls (CON group, $n=13$ ). OCT images were obtained from the dorsal foot, at baseline $\left(33^{\circ} \mathrm{C}\right)$ and $30 \mathrm{~min}$ following skin heating.

Results At baseline, microvascular density was higher in DFU compared with CON $(21.9 \% \pm 11.5 \%$ vs $14.3 \% \pm 5.6 \%$, $\mathrm{p}=0.048$ ). Local heating induced significant increases in diameter, speed, flow rate and density in all groups (all $p<0.001$ ), with smaller changes in diameter for the DFU group $(94.3 \pm 13.4 \mu \mathrm{m})$, compared with CON group $(115.5 \pm 11.7 \mu \mathrm{m}, \mathrm{p}<0.001)$ and DNU group (106.7 $\pm 12.1 \mu \mathrm{m}, p=0.014)$. Heating-induced flow rate was lower in the DFU group $(584.3 \pm 217.0 \mathrm{pL} / \mathrm{s})$ compared with the CON group $(908.8 \pm 228.2 \mathrm{pL} / \mathrm{s}, \mathrm{p}<0.001)$ and DNU group $(768.8 \pm 198.4 \mathrm{pL} / \mathrm{s}, \mathrm{p}=0.014)$, with changes in density also lower in the DFU group than CON group $(44.7 \% \pm 15.0 \%$ vs $56.5 \% \pm 9.1 \%, p=0.005)$.

Conclusions This proof of principle study indicates that it is feasible to directly visualize and quantify microvascular function in people with diabetes; and distinguish microvascular disease severity between patients.

\section{INTRODUCTION}

Diabetic foot disease and ulceration is a major complication of diabetes mellitus, with a lifetime incidence as high as $25 \% .^{1}$ The incidence of diabetic foot disease and ulceration is increasing due to the high worldwide prevalence of diabetes, increasing obesity rates and the longer life expectancy of people with diabetes. In 2016, the global prevalence of foot ulceration in patients with diabetes was $6.3 \%,{ }^{2}$ with a lower limb amputation performed every $30 \mathrm{~s}^{3}$ This condition is also

\section{Significance of this study}

What is already known about this subject?

- Diabetic subjects possess abnormal cutaneous microvascular function, which may induce and/or exacerbate microvascular disease and complications. The study of microvessels in diabetics has been constrained by the lack of suitable tools to visualize and quantify microvascular structure and function in vivo.

What are the new findings?

- This is the first study that has directly visualized and quantified the function and structure of skin microvessels as small as $\sim 30 \mu \mathrm{m}$ in diabetic subjects and matched controls, both at rest and in response to physiological stimulation.

- Optical coherence tomography (OCT)-derived measures provide more comprehensive skin microvascular hemodynamics compared to conventional techniques.

- Our study illustrates the feasibility of an exciting and highly powerful new non-invasive imaging technique which can distinguish between patients and healthy controls and identify microvascular abnormalities that are disease severity specific in patients with diabetes.

associated with high economic burden due to the presence of infection and other complications and high recurrence rates. ${ }^{45}$

Diabetic foot ulceration is a chronic severe complication of diabetes associated with neuropathy and/or arteriosclerotic peripheral vascular diseases in the lower limb, ${ }^{6}$ alongside microvascular abnormalities. There are two pathogenic theories pertaining to microvascular disease in people with diabetes; the 'capillary steal syndrome theory' and the 'hemodynamic hypothesis'. In the former, sympathetic autonomic neuropathy 


\section{Significance of this study}

How might these results change the focus of research or clinical practice?

- For the clinician, the techniques we introduce in this study may prove useful for diagnosing early stages of microvascular disease in high-risk patients, in characterizing disease progression and in assessing the efficacy of therapeutic interventions. Future studies may be directed to longitudinally assess larger cohorts of patients and to determine the utility of OCT in risk stratifying the diabetic foot, predicting outcomes and instituting early treatment.

- For scientists, using a combination of OCT assessment and simultaneous microdialysis delivery of specific pathway antagonist will allow pharmaco-dissection of individual pathways responsible for the regulation of cutaneous microvascular dysfunction/function in health and disease.

in the lower limb causes a loss of vasoconstrictor tone and subsequent alteration in blood flow which increases arteriovenous shunting ${ }^{68}$ and reduces nutritive blood flow. ${ }^{9}$ The 'hemodynamic hypothesis ${ }^{10}$ proposes that hyperglycemia promotes oxidative stress and cell damage, limits the production of nitric oxide (NO) and increases capillary pressure, ${ }^{11}$ leading to adaptation and remodeling, thickening of capillary basement membranes, microvascular sclerosis and finally, limitation of hyperemia and loss of autoregulation. ${ }^{810} 12$ Although debate continues regarding these theories of microvascular impairment in diabetes, abnormal cutaneous microvascular function and structure are a common and fundamental feature, which lead to further complications such as poor wound healing ${ }^{813}$ and, in some cases, amputation. The visualization and quantification of microvascular structure and function is crucial to understanding pathophysiology as well as determining patient risk, disease progression and treatment efficacy.

Several methods have previously been proposed to assess the skin microcirculation in patients with diabetes, including capillary microscopy $(\mathrm{CM}),{ }^{14}$ transcutaneous oxygen pressure assessment $\left(\mathrm{TcPO}_{2}\right),{ }^{14-16}$ laser Doppler flowmetry (LDF) ${ }^{1314}$ and laser Doppler imaging (LDI) ${ }^{1718} \mathrm{CM}$ is usually limited to nail-beds in humans, while LDF provides an indirect and qualitative assessment of 'flux' and is not capable of visualizing or quantifying individual or regional microvascular anatomy or blood flow. LDI can resolve regional Doppler with a resolution of $\sim 100 \mu \mathrm{m}$, however the vessels pertinent to skin microvascular health are much smaller $(\sim 10-50 \mu \mathrm{m})$ and this technique does not visualize individual vessels or their density. ${ }^{19}$ These techniques therefore possess serious limitations in their capacity to characterize skin microcirculatory structure and function and they have not been widely adopted.

Optical coherence tomography (OCT) is non-invasive ultrahigh-resolution optical imaging technique which is capable of visualizing and quantifying skin microvessels as small as $\sim 30 \mu \mathrm{m}$ in humans. In our recent studies, we have shown that OCT is capable of providing high-resolution images and accurate quantification of cutaneous microvessel structure and function, both at rest and in response to physiological stimulation (eg, responses to local heating)..$^{20} 21$ The purpose of this study was to apply OCT in people with diabetes, with and without foot ulceration, and compare these responses to a healthy age and sex-matched control group. We hypothesized that OCTbased parameters would differentiate between control and diabetic subjects in terms of their skin microvascular structure and function.

\section{RESEARCH DESIGN AND METHODS \\ Subject characteristics}

Patients with diabetes mellitus and a diagnosed foot ulcer (DFU group, $n=13$ ) were recruited and enrolled if they had a history of diabetes for more than 1 year and at least one current diabetic foot ulcer, or a history ( $<3$ months) of foot ulceration. Subjects with previous amputation distal to the metatarsals and/or foot deformity were included. All subjects required at least one palpable pedal pulse and/or an ankle-brachial pressure index of higher than 0.7 and/or a toe systolic blood pressure of greater than $70 \mathrm{~mm} \mathrm{Hg}$. Patients who had a history of endovascular treatment involving stenting or bypass grafting on their assessed leg were excluded from this study.

The diabetic group without foot ulcers (DNU group, $\mathrm{n}=10$ ) were recruited and enrolled if they had a history of diabetes of more than 1 year and had never experienced diabetic foot ulceration. Pharmacotherapy, wound care, footwear and podiatric care of DFU and DNU groups were maintained, according to their current standard of care and each subject received follow-up irrespective of involvement in the study.

The control group were recruited from the community (CON group, $n=13$ ). They were screened to ensure that they were free from diabetes, cardiovascular, metabolic diseases and they were all non-smokers. One leg for each control participant was randomly selected for assessment. Subject characteristics are presented in table 1.

\section{Study design}

The study was undertaken in a quiet and temperaturecontrolled room $\left(23^{\circ} \mathrm{C}\right)$ in the Cardiovascular Research Laboratory, School of Human Sciences (Exercise and Sports Science), The University of Western Australia. All participants were studied at the same time of day (09:00-11:00). All participants were asked to fast or have a light breakfast at least 4 hours prior to testing. They all abstained from alcohol, chocolate, caffeine, tea and exercise for $>12$ hours prior to testing. The skin site on the dorsum of the foot was shaved 24 hours before assessment so that microtrauma from shaving did not affect measurement. At the commencement of the test session, participant's demographic data were documented, including age, gender, height and weight.

The participants lay supine in semi-Fowler's position whereby the assessed leg was constrained within 
Table 1 Subject characteristics

\begin{tabular}{|c|c|c|c|c|}
\hline & $\begin{array}{l}\text { CON } \\
(n=13,5 \bigcirc 8\end{array}$ & $\begin{array}{l}\text { DNU } \\
\left.(\mathbf{n}=10,5+5)^{\prime}\right)\end{array}$ & $\begin{array}{l}\text { DFU } \\
(\mathbf{n = 1 3 , 5}+\mathbf{8})\end{array}$ & $\begin{array}{l}\text { P value } \\
\text { (one-way } \\
\text { ANOVA) }\end{array}$ \\
\hline BMI $\left(\mathrm{kg} / \mathrm{m}^{2}\right)$ & $26.0 \pm 3.3$ & $29.1 \pm 7.0$ & $31.7 \pm 5.5^{\star}$ & 0.03 \\
\hline \multicolumn{5}{|l|}{ Blood pressure (mm Hg) } \\
\hline Mean arterial pressure & $90 \pm 8$ & $88 \pm 10$ & $95 \pm 8$ & 0.17 \\
\hline Resting heart rate (beats per minute) & $60 \pm 8$ & $74 \pm 13 \dagger$ & $73 \pm 10 \dagger$ & $<0.01$ \\
\hline Body temperature $\left({ }^{\circ} \mathrm{C}\right)$ & $36.5 \pm 0.3$ & $37.1 \pm 0.4 \dagger$ & $36.9 \pm 0.5^{\star}$ & $<0.01$ \\
\hline HbA1c (\%) & NA & $7.9 \pm 1.3$ & $8.4 \pm 2.1$ & 0.54 \\
\hline
\end{tabular}

Type of diabetes

\begin{tabular}{|c|c|c|c|}
\hline DM type 1 & - & 1 & 3 \\
\hline DM type 2 & - & 9 & 10 \\
\hline Duration of diabetes (years) & - & $18.4 \pm 8.2$ & $23.6 \pm 11.2$ \\
\hline \multicolumn{4}{|l|}{ Other medical condition/risk factors } \\
\hline Hypertension & 1 & 2 & 9 \\
\hline Hypercholesterolemia & 0 & 5 & 8 \\
\hline History of cardiovascular diseases & 0 & 1 & 3 \\
\hline History of cerebrovascular diseases & 0 & 0 & 0 \\
\hline Current smoker; ex-smoker & $0 ; 2$ & $0 ; 5$ & $0 ; 5$ \\
\hline \multicolumn{4}{|l|}{ Medication } \\
\hline Insulin injection & 0 & 4 & 7 \\
\hline Non-insulin antidiabetic injection & 0 & 2 & 2 \\
\hline Oral antidiabetic & 0 & 5 & 6 \\
\hline Antihypertension & 1 & 2 & 9 \\
\hline Antihypercholesterolemia & 0 & 5 & 8 \\
\hline
\end{tabular}

Data are presented in mean \pm SD.

*Significantly different from control group at $p<0.05$.

†Significantly different from control group at $p<0.01$.

ANOVA, analysis of variance; BMI, body mass index; CON, control; DFU, diabetic foot ulcer; DM, diabetes mellitus; DNU, diabetic non-ulcer; HbA1c, glycated hemoglobin; NA, not applicable.

a custom-designed boot, supported by a customized foam pad. This aimed to minimize leg/foot movement during assessment. After participant positioning and placing the OCT/LDF probes, a 20 min quiet rest period was observed, with brachial blood pressure assessment obtained (Dinamap V100, GE Healthcare, USA). Body temperature (BT) was measured using an ear thermometer (MC-522, Omron Healthcare, Japan) prior to the local heating protocol. Immediately after OCT baseline images were obtained, a local heating disk (PF450, Perimed, Stockholm) which housed the OCT probe was heated at a rate of $1^{\circ} \mathrm{C} / 10 \mathrm{~s}$, from $33^{\circ} \mathrm{C}$ to $44^{\circ} \mathrm{C}$. Once $44^{\circ} \mathrm{C}$ was attained, the heater disk and skin temperature were maintained at $44^{\circ} \mathrm{C}$ for a further $30 \mathrm{~min},{ }^{22} 23$ whereupon the final postheating data were collected.
While OCT assessments were collected, simultaneous recordings of the cutaneous red blood cell flux were obtained using LDF. All assessments were obtained from a location immediately adjacent to the placement of the OCT probe, on the dorsum of the foot. Noninvasive blood pressure measurements were continuously recorded from the finger using a Finometer (Finapres NOVA, Amsterdam, the Netherlands).

\section{Instrumentation and analysis Laser Doppler flowmetry}

Red blood cell flux was measured on the dorsum of the foot using a 7 Doppler array laser probe (LDF, model 413, PeriFlux 5000 System; Sweden), with integrated thermostatic probe holder (PF450, Perimed), positioned 
adjacent to the OCT probe. OCT/LDF probe holders were affixed using double-sided adhesive rings. A skin temperature sensor (MLT409; ADInstruments, Bella Vista, NSW, Australia) was placed between the two thermostatic probe holders (OCT and LDF). Real-time flux signals were relayed and graphed via PowerLab onto a laptop running LabChart V.8 software (ADInstruments, Sydney, Australia) for offline analysis.

LDF-derived flux analysis at baseline and postlocal heating was performed across the same time period as that used to obtain the OCT images. Cutaneous vascular conductance (CVC) was calculated as LDF-derived flux in arbitrary perfusion units (PU), divided by mean arterial blood pressure (Finometer). Individual graphs were constructed by averaging the values of flux in $30 \mathrm{~s}$ bins from baseline until the end of the local heating period and the total local heating responses were calculated as area under the curve (AUC) from the beginning of rapid increase of skin temperature until the end of local heating period, as described above. Local heating responses for flux and CVC were also measured as percentage changes from baseline and postlocal heating.

\section{Optical coherence tomography}

OCT imaging was performed using a commercial imaging system (Telesto III, Thorlabs, Germany) with central wavelength of $1300 \mathrm{~nm}$ and an axial resolution of $5 \mu \mathrm{m}$ in tissues (assuming refractive index of 1.43 for the skin). ${ }^{24}$ Scanning was performed using a detachable imaging probe (LSM03, Thorlabs) with a lateral resolution of $13 \mu \mathrm{m}$. The probe was attached to a $5 \mathrm{df}$ articulated arm and probe holder to minimize motion during scanning. A custom spacer was designed and fabricated using a 3D printer (Form 2, Formlabs, MA, USA), to ensure a standard distance between the imaging probe and skin surface. OCT imaging was performed through the central bore of a thermostatic probe holder (PF450, Perimed). A small drop of ultrasound gel was placed between the skin and a transparent square microscope coverslip $(8 \times 8 \mathrm{~mm})$ attached to the thermostatic probe holder. This provided a flat imaging surface, eliminating imaging artifacts due to the surface shape of the subject's skin. $^{25}$

OCT data were acquired over a field of view with dimensions of $5 \times 5 \times 2.5 \mathrm{~mm}$ (length $\times$ width $\times$ depth), at a sampling of $1000 \times 5000 \times 1024$ pixels $(\mathrm{X} \times \mathrm{Y} \times \mathrm{Z})$. The imaging light beam in OCT is weakly focused, providing high spatial resolution over a depth of focus of a few hundred microns. The OCT beam was set to assess cutaneous tissue to a depth of approximately $300 \mu \mathrm{m}$ below the skin surface. This ensured that the appropriate vascular tissue was assessed. Individual OCT measurements (A scan) were acquired at a rate of $76 \mathrm{kHz}$ and the total acquisition time was approximately $90 \mathrm{~s}$. We found this acquisition time to be well tolerated by our subjects, with minimal movement artifact. The stack of A scans was collected and speckle decorrelation analysis performed. Further details of this image acquisition and analysis are

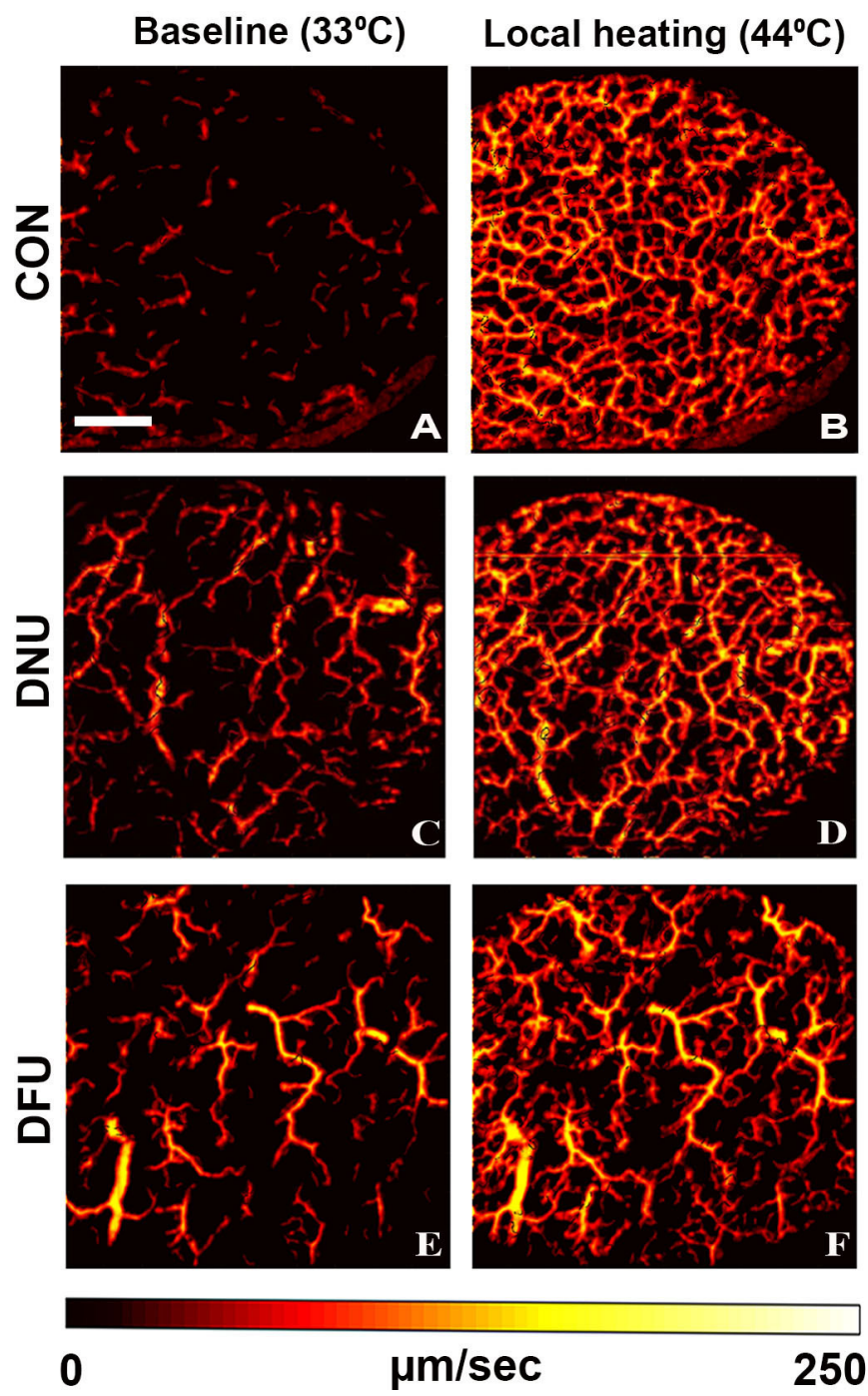

Figure 1 Representative OCT-derived images from CON (top: A, B), DNU (middle: C, D) and DFU (bottom: E, F) subjects at baseline (left) and during LH (right). Blood vessels are color coded to indicate flow speed $(\mu \mathrm{m} / \mathrm{s})$. The white scale bar represents $500 \mu \mathrm{m}$. CON, control; DFU, diabetic foot ulcer; DNU, diabetic non-ulcer; LH, local heating; OCT, optical coherence tomography.

described elsewhere. ${ }^{20}$ In brief, the characteristics of the speckle noise are related to blood flow speed, with faster blood flow giving rise to more rapid fluctuations in the speckle noise. Speckle indicating blood vessels is automatically delineated from the surrounding static tissue using standard imaging processing techniques, with the speckle fluctuations providing an estimate of flow speed at each point. We calculated the average vessel diameter (units: microns) and average flow speed within vessels (units: microns per second) over the entire scanning field of view. We also computed the average flow in each vessel (units: picolitres/second). Finally, we computed an estimate of vessel density by generating a two-dimensional projection image of the blood vessels (shown in figure 1) and quantifying the pixels that lay on a blood vessel as a percentage of the total $5 \mathrm{~mm} \times 5 \mathrm{~mm}$ field of view. 
Local heating responses of OCT-derived diameter, speed, flow and density are reported as percentage changes between baseline and postlocal heating (relative changes). Due to severe tremor during OCT scanning, images from one participant in DFU group were eliminated from OCT analysis.

\section{Statistical analysis}

Sample size calculation was based on the published data of Sandeman $e t a l^{26}$ which reported the difference in skin microvascular responses to local heating stimuli between three groups: non-insulin-dependent, insulin-dependent diabetic subjects and controls. Mean and variance data derived from this study were assessed using the formula of Hozo et $_{\text {al. }}{ }^{27}$ Assuming $\alpha=0.05$ and $\beta=0.8$, the minimum number of subjects required to establish significance is 7 per group ( $\mathrm{G}^{*}$ Power V.3.1.9.7).

Data are presented using graphing software (PRISM V.8.1, GraphPad, La Jolla, CA, USA). All data are reported as means \pm SD unless stated otherwise and statistical significance was assumed at $\mathrm{p}<0.05$. A two-way repeated measures analysis of variance (ANOVA) was performed to calculate differences between groups, before and after local heating (time factor), for both OCT and LDF outcome measures. If the significant interaction and/ or main effects were detected, post hoc analysis by Fisher's least significant difference was performed to determine the differences between groups. One-way ANOVA analysis was performed between groups where data without a time factor (eg, baseline data) were compared.

\section{RESULTS}

\section{Participant characteristics}

There were no differences in age or blood pressure (systolic, diastolic and mean) between groups when oneway ANOVA was performed. However, body mass index was significantly different between groups $(p=0.03)$, with post hoc tests revealing higher values in the DFU group compared with the CON group $(\mathrm{p}=0.010)$. Resting heart rate (RHR) and BT were significantly different between groups (all $\mathrm{p}<0.01$ ), with RHR and BT higher in DFU (RHR $\mathrm{p}=0.004$; BT $\mathrm{p}=0.02$ ) and DNU (RHR $\mathrm{p}=0.002$; BT $\mathrm{p}=0.002)$ than CON. However, RHR and BT were within the normal range. Further details of participant characteristics are shown in table 1.

\section{Baseline characteristics and the effects of local heating on LDF-derived parameters}

Table 2 summarizes baseline characteristics and LDF responses to $30 \mathrm{~min}$ of local heating parameters in each group. There was a significant difference (one-way ANOVA) in foot skin temperature at rest between groups $(\mathrm{p}<0.001)$, whereby the foot skin temperature in DFU $>\mathrm{D}$ $\mathrm{NU}>\mathrm{CON}$ group $(\mathrm{CON}$ vs DNU $\mathrm{p}=0.005$; $\mathrm{CON}$ vs $\mathrm{DFU}$ $\mathrm{p}<0.001 ; \mathrm{DNU}$ vs DFU $\mathrm{p}=0.002)$. There were no significant

Table 2 Cutaneous microvessel local heating responses using laser Doppler fluxometry (LDF-derived parameters)

\begin{tabular}{|c|c|c|c|c|c|c|c|c|c|c|}
\hline & CON & & & DNU & & & DFU & & & ANOVA \\
\hline & BL & LH & $\begin{array}{l}\text { P value } \\
\text { (BL vs } L H)\end{array}$ & BL & LH & $\begin{array}{l}\text { P value } \\
\text { (BL vs } L H)\end{array}$ & BL & LH & $\begin{array}{l}\text { P value } \\
\text { (BL vs } \mathrm{LH} \text { ) }\end{array}$ & $P$ value \\
\hline Flux (PU) & $33 \pm 13$ & $171 \pm 38$ & $<0.001$ & $28 \pm 17$ & $135 \pm 48 \dagger$ & $<0.001$ & $35 \pm 18$ & $135 \pm 36+$ & $<0.001$ & $\begin{array}{l}0.023(\text { two- } \\
\text { way RM)* }\end{array}$ \\
\hline$\%$ change flux & $498 \pm 237$ & & & $482 \pm 243$ & & & $380 \pm 262$ & & & $\begin{array}{l}0.427 \text { (one } \\
\text { way) }\end{array}$ \\
\hline $\begin{array}{l}\text { CVC } \\
(\mathrm{PU} \cdot \mathrm{mm} / \mathrm{Hg})\end{array}$ & $0.34 \pm 0.15$ & $1.80 \pm 0.48$ & $<0.001$ & $0.31 \pm 0.17$ & $1.52 \pm 0.56$ & $<0.001$ & $0.37 \pm 0.20$ & $1.45 \pm 0.34$ & $<0.001$ & $\begin{array}{l}0.067 \text { (two- } \\
\text { way RM) }\end{array}$ \\
\hline$\%$ change CVC & $513 \pm 238$ & & & $472 \pm 263$ & & & $389 \pm 273$ & & & $\begin{array}{l}0.457 \text { (one } \\
\text { way) }\end{array}$ \\
\hline $\begin{array}{l}\text { MABP, finger } \\
(\mathrm{mm} \mathrm{Hg})\end{array}$ & $100.1 \pm 12.7$ & $99.6 \pm 13.5$ & 0.757 & $92.6 \pm 18$ & $94.6 \pm 18.1$ & 0.283 & $96.5 \pm 14$ & $96 \pm 14$ & 0.756 & $\begin{array}{l}0.516 \text { (two- } \\
\text { way RM) }\end{array}$ \\
\hline $\begin{array}{l}\text { Resting skin } \\
\text { temperature }\left({ }^{\circ} \mathrm{C}\right)\end{array}$ & $29.6 \pm 1.2$ & & & $31.3 \pm 1.3 \dagger$ & & & $33.1 \pm 1.4 † \ddagger$ & & & $\begin{array}{l}<0.001 \\
\text { (one way) }\end{array}$ \\
\hline $\begin{array}{l}\text { LDF heat unit } \\
\text { temperature }\left({ }^{\circ} \mathrm{C}\right)\end{array}$ & $33.1 \pm 0.3$ & $44.0 \pm 0$ & $<0.001$ & $33.0 \pm 0$ & $44.0 \pm 0$ & $<0.001$ & $33.3 \pm 0.5$ & $44.0 \pm 0$ & $<0.001$ & \\
\hline $\begin{array}{l}\text { OCT heat unit } \\
\text { temperature }\left({ }^{\circ} \mathrm{C}\right)\end{array}$ & $33.1 \pm 0$ & $44.2 \pm 0$ & $<0.001$ & $33.1 \pm 0$ & $44.2 \pm 0$ & $<0.001$ & $33.3 \pm 0.4$ & $44.2 \pm 0$ & $<0.001$ & \\
\hline
\end{tabular}

Data are presented in mean $\pm S D$. Two-way repeated measures ANOVA ( $p$ value indicated interaction between time ${ }^{*}$ group factors) was used to test the LDF-derived flux and CVC at baseline and at the end of local heating between groups, while \% changes were tested using one-way ANOVA.

Post hoc $p$ values for baseline and local heating responses within groups are detailed in the columns.

*Significantly different from control group at $\mathrm{p}<0.05$,

†Significantly different from control group at $p<0.01$.

$¥$ Significantly different from DNU group at $p<0.01$.

ANOVA, analysis of variance; BL, baseline; CON, control; CVC, cutaneous vascular conductance; DFU, diabetic foot ulcer; DNU, diabetic non-ulcer; LDF, laser Doppler flowmetry; LH, local heating; MABP, Mean Arterial Blood Pressure; OCT, optical coherence tomography; PU, perfusion unit; RM, repeated measures. 


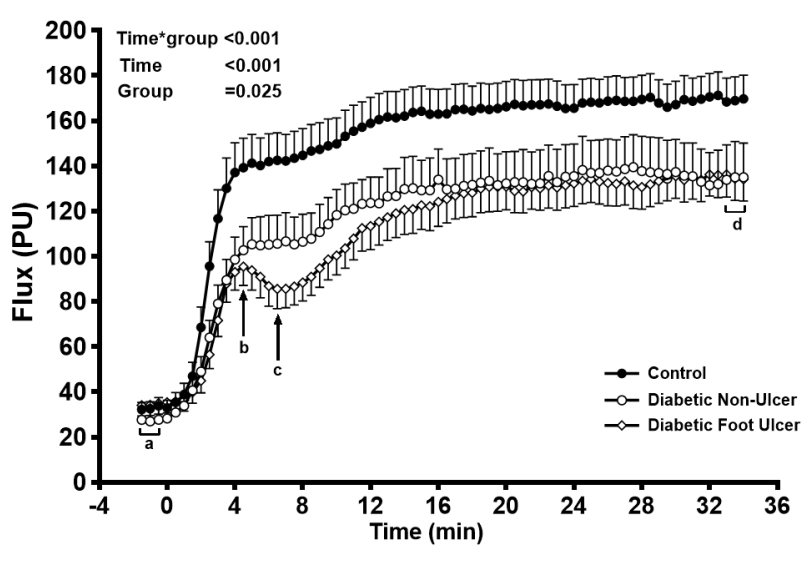

Baseline $\left(33^{\circ} \mathrm{C}\right)$

Figure 2 Graph shows cutaneous red cell LDF-derived flux mean (SEM) from CON (black circle), DNU (white circle) and DFU (white rhombus) groups at rest $\left(33^{\circ} \mathrm{C}\right)$, during rapid local heating from $33^{\circ} \mathrm{C}$ to $44^{\circ} \mathrm{C}$ and constant heating at $44^{\circ} \mathrm{C}$. Point a (baseline) and point $\mathrm{d}$ (end of local heating) show the same time point as optical coherence tomography (OCT) scan; b: transient peak; c: nadir. A two-way repeated measures analysis of variance (ANOVA) was performed to analyze the differences of LDF-derived flux across the time from baseline until the end of local heating between groups. One-way ANOVA was performed to analyze LDF-derived flux at transient peak, nadir, and total area under the curve (AUC) heating responses. CON, control; DFU, diabetic foot ulcer; DNU, diabetic non-ulcer; LDF, laser Doppler flowmetry; PU, perfusion unit.

changes in blood pressure during local heating (time $\mathrm{p}=0.735$; group $\mathrm{p}=568$; time* group $\mathrm{p}=0.516$ ).

We compared LDF-derived flux and CVC at baseline and following prolonged local heating using two-way repeated measures ANOVA. This revealed a significant main effect of time $(p<0.001)$ but no significant main effect for group (flux $\mathrm{p}=0.107$; $\mathrm{CVC} \mathrm{p}=0.316$ ). Time*group interaction for LDF-derived flux was significant $(p=0.023)$, but not significant when expressed in CVC ( $p=0.067)$. Baseline LDF-derived flux and CVC were not different between groups (table 2).

LDF-derived flux greatly increased at the end of the plateau phase following $30 \mathrm{~min}$ of local heating, compared with the baseline state, in all groups (all $\mathrm{p}<0.001$, table 2 ). LDF-derived flux after $30 \mathrm{~min}$ of local heating was lower in DFU group than CON group ( $\mathrm{p}=0.003$ ) and $\mathrm{DNU}$ group $(p=0.007)$. Statistical comparisons revealed no significant differences between groups in terms of relative increases from baseline in response to heating $(p=0.427)$.

In keeping with the above LDF-derived flux results, there were significant increases in skin conductance in all groups following $30 \mathrm{~min}$ of local heating at $44^{\circ} \mathrm{C}$ (all $\mathrm{p}<0.001)$. The skin conductance relative changes from baseline values also showed no significant differences between groups $(\mathrm{p}=0.457)$ (see further details in table 2$)$.

Figure 2 shows the mean values of LDF-derived flux in $30 \mathrm{~s}$ bins from baseline (point a) until the end of the rapid local heating (point d) period. Two minutes after completing the rapid local heating to $44^{\circ} \mathrm{C}$, each group reached a transient peak in LDF (point $b, p=0.014$, oneway ANOVA). This transient peak was lower in DNU than CON $(102.7 \pm 33.0 \mathrm{PU}$ vs $135.5 \pm 46.5 \mathrm{PU}, \mathrm{p}=0.029)$ and lower again in DFU subjects $(95.5 \pm 31.2 \mathrm{PU}$ vs 135.5 $\pm 46.5 \mathrm{PU}, \mathrm{p}=0.006$ ). Following these transient peaks, the skin flux slowly rose until it reached a plateau in CON and in the DNU groups, whereas in DFU subjects there was a transient drop (nadir, point c) in skin flux, before values rose to a plateau phase in all groups (point $\mathrm{d}, \mathrm{p}=0.003$, one-way ANOVA). The temporal pattern of LDF skin flux therefore differed between groups. The total local heating response (AUC) of LDF-derived flux was significantly different between groups $(\mathrm{p}<0.001$, oneway ANOVA), whereby DFU group $(3831 \pm 358.0 \mathrm{PU} \cdot \mathrm{min}$, $\mathrm{p}<0.001)$ and DNU group $(4044 \pm 379.2 \mathrm{PU} \cdot \mathrm{min}, \mathrm{p}<0.001)$ possessed lower responses compared with CON group $(5141 \pm 415.7 \mathrm{PU} \cdot \mathrm{min})$. No differences were apparent between the DFU and DNU groups $(p=0.198)$.

\section{Baseline characteristics and the effects of local heating on OCT-derived parameters}

Baseline characteristics and local heating responses for OCT-derived parameters (diameter, speed, flow rate and density) for each group are summarized in figure 3 . Two-way repeated measures ANOVA revealed significant interaction effects for time*group for all OCT-derived parameters and main effect for time. However, there were no significant main effects of group for any OCTderived parameters (figure 3).

Figure 1 shows representative images of one individual's OCT-derived images from the dorsum of the foot from each group at baseline (left panel: 3A, 3C, 3E) and in response to local heating (right panel: 3B, 3D, $3 \mathrm{~F}$ ). At baseline, OCT-derived density (vessel recruitment) was higher in DFU compared with control group $(21.9 \% \pm 11.5 \%$ vs $14.3 \% \pm 5.6 \%, \mathrm{p}=0.048)$ (figure 3$)$, while the larger diameter apparent in the DFU group compared with CON (figure 1) was not significant $(p=0.07)$.

There were significant increases in OCT-derived diameter, speed, flow rate and density following prolonged heating in all groups (all $\mathrm{p}<0.001$, figure 3 ). Compared with CON group $(115.5 \pm 11.7 \mu \mathrm{m})$, OCT-derived diameters were significantly lower in the DFU group $(94.3 \pm 13.4$, $\mathrm{p}<0.001)$. The DFU group also differed from the DNU group $(106.7 \pm 12.1 \mu \mathrm{m}, \mathrm{p}=0.014)$. The relative changes in OCT-derived diameter from baseline in response to local heating were significantly different between groups $(p<0.001$, one-way ANOVA) where the responses were much lower in the DFU group $(18.8 \% \pm 13.6 \%, \mathrm{p}<0.001)$ and the DNU group $(35.8 \% \pm 17.2 \%, \mathrm{p}=0.044)$ compared with CON group $(53.1 \% \pm 25.1 \%)$, and the difference between the DFU and DNU groups was borderline significant $(\mathrm{p}=0.050)$.

Compared with the DNU group $(84.6 \pm 10.0 \mu \mathrm{m} / \mathrm{s})$, OCT-derived speed was slightly lower in the DFU group $(78.7 \pm 8.6, \mathrm{p}=0.051)$. OCT-derived relative changes in 
Diameter

Speed
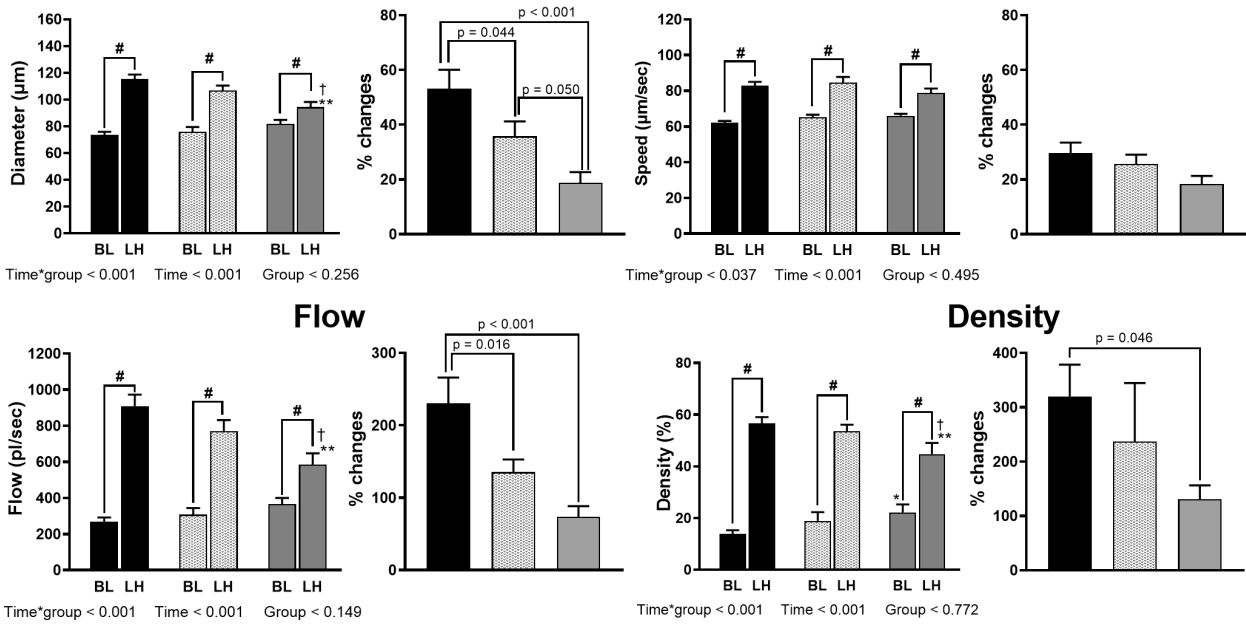

Density

- Control Diabetic Non-Ulcer $\square$ Diabetic Foot Ulcer

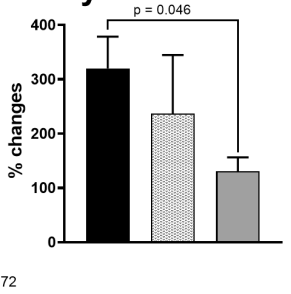

Figure 3 OCT-derived parameters (diameter, speed, flow rate, and density) at baseline and at the end of 30 min prolonged local heating. The local heating responses relative to their baseline are shown as $\%$ changes. Data are presented in mean (SEM). A two-way repeated measures analysis of variance (ANOVA) was performed to calculate differences between groups, before and after heating for all OCT-derived parameters. One-way ANOVA analysis was performed to analyze relative changes of all OCT-derived parameters. \#Significant difference $(p<0.001)$ of local heating responses from their baseline within the same group. *Significantly different from control group at $p<0.05$. ${ }^{*}$ Significantly different from control group at $p<0.01$. $†$ Significantly different from diabetic non-ulcer (DNU) group at $\mathrm{p}<0.05$. BL, baseline; $\mathrm{LH}$, local heating; OCT, optical coherence tomography.

speed from baseline during heating were not significantly different between groups $(\mathrm{p}=0.077)$.

Compared with the CON group $(908.8 \pm 228.3 \mathrm{pL} / \mathrm{s}$, $\mathrm{p}<0.001)$ and DNU group $(768.8 \pm 198.4 \mathrm{pL} / \mathrm{s}, \mathrm{p}=0.014)$, OCT-derived flow rate during local heating was lower in the DFU group $(584.3 \pm 217.0 \mathrm{pL} / \mathrm{s})$ and the difference between the CON and DNU groups was borderline significant $(\mathrm{p}=0.055)$. The relative changes in OCT-derived flow rate from baseline in response to local heating were significantly different between groups $(\mathrm{p}<0.001)$. Compared with CON group $(230.5 \% \pm 128.1 \%)$, OCT-derived relative changes in flow rate from baseline in response to heating were lower in the DFU group $(73.4 \% \pm 51.6 \%, \mathrm{p}<0.001)$ and the DNU group $(135.2 \% \pm 55.6 \%, \mathrm{p}=0.016)$.

Compared with the CON group $(56.5 \pm 9.1, \mathrm{p}=0.005)$ and DNU group $(53.5 \% \pm 8.0 \%, \mathrm{p}=0.047)$, OCT-derived density during local heating was lower in DFU group $(44.7 \% \pm 15.0 \%)$. The relative changes in OCT-derived density from baseline in response to local heating were significantly different between groups $(\mathrm{p}=0.038)$. Compared with CON group $(320.1 \% \pm 210.6 \%)$, OCTderived relative changes in density from baseline in response to heating were also lower in the DFU group $(130.5 \% \pm 89.9 \%, \mathrm{p}=0.046)$.

\section{DISCUSSION}

The purpose of this study was to establish the feasibility of using OCT to visualize and quantify cutaneous microvascular structure and function in people with diabetes in response to the physiological stimulus of skin heating. By recruiting people with diabetes, with and without foot ulcers, and comparing them to healthy age and sex-matched controls, we hoped to ascertain whether OCT-derived measures could distinguish between clinical populations. Our study has several important findings: (i) that differences exist between diabetic subgroups and controls in terms of resting OCT-derived visual characteristics, (ii) that local heating is a potent stimulus that increases OCT-derived outcomes such as microvessel diameter, speed, flow and density, (iii) that microvascular reserve, or capacity for microvascular functional parameters to respond to heating, is impaired in patients with diabetes, with greater impairment in those with established ulceration.

The most compelling outcome of our study was that the change in OCT-derived parameters, from resting values in response to imposed skin heating (figure 3), was impaired in people with diabetes, and further attenuated in those with foot ulcers. This clear and consistent stepwise impairment, whereby $\mathrm{CON}>\mathrm{DNU}>\mathrm{DFU}$ across all parameters, strongly suggests that OCT is capable of discriminating between subjects with different degrees of microvascular dysfunction. The $\%$ change panels in figure 3 reflect differences that exist between groups in response to heating, but also in baseline data. Our careful inspection of individual data, such as the examples provided in figure 1, suggests to us that important differences exist between controls and participants with diabetes at rest, as well as in response to heating. There was consistent appearance of larger highly perfused vessels in the diabetic groups at rest, but sparse appearance of smaller, possibly more nutritive, vessels. In response to heating, the perfusion of smaller vessels is clearly evident in controls, whereas in diabetic groups 
larger vessels remain highly perfused, with a lesser degree of small vessel engorgement. This is the first time, to our knowledge, that visualization of skin microvessels has been reported in different clinical populations and in response to physiological stimulation. Our observations are broadly consistent with the proposal that nutritive blood flows are impaired in diabetic microvascular disease, while perfusion of larger non-nutritive microvessels may be paradoxically enhanced. It is notable that resting skin temperatures were higher in the diabetic subjects $\left({ }^{\circ} \mathrm{C}\right.$ : DFU $>$ DNU $\left.>\mathrm{CON}\right)$, which accords with the visual OCT evidence and also with the common clinical observation that diabetic skin is 'warm'. It is also notable that LDF flux values did not reflect the pattern evident in the OCT and skin thermistor data, which highlights the limitations of this approach.

Our study was not specifically designed to examine the two prevailing paradigms pertaining to microvascular disease in people with diabetes; the capillary steal versus hemodynamic hypotheses. However, we think that future OCT-driven research, perhaps involving prospective time course studies of the progressive evolution of microvascular disease, may shed important light on pathophysiology. Another promising future opportunity is the combination of OCT visualization and quantification of in vivo functional responses alongside skin biopsy techniques. In recent studies, biopsies performed in the lower leg have revealed lower ${ }^{28}$ and higher ${ }^{29}$ microvascular density in diabetic versus control subjects, perhaps depending on the disease type and severity.

We used local heating because it is a simple, easily administered and safe approach to assessing abnormalities in microvessel function and structure (eg, density) in response to a common and relevant physiological stressor. In contrast to the preserved or increased values for diameter, speed, flow and density apparent at rest in diabetic subjects, responses to imposed (and identical) heating stimuli revealed consistently diminished responses in both diabetic groups, with more exaggerated impairment in the DFU group. These observations reinforce the importance of examining vascular responses to physiologically relevant stimuli in humans, in addition to obtaining quiescent data. Cutaneous vasodilation in response to local heating involves a complex integrated and redundant group of neural and intrinsic mechanisms, ${ }^{30}$ including axonal reflexes ${ }^{31}$ and the release of $\mathrm{NO}^{23}{ }^{31-33}$ endothelium-derived hyperpolarizing factors, ${ }^{23}$ and other autocrines. In healthy non-glabrous (hairy) skin, rapid non-painful local heating (up to $42^{\circ} \mathrm{C}$ ) classically induces a bimodal response,${ }^{31}$ with an initial peak mediated by an axon reflex, ${ }^{31}$ followed by a transient nadir, and subsequent plateau phase. ${ }^{31}{ }^{32}$ In this study we chose a modified local heating protocol which aimed to induce maximal vasodilation and so assess functional and structural aspects of microvascular dilation. ${ }^{20}$ The impaired heating responses we observed in the DFU and DNU groups may be due to loss of neurogenic vasodilation and/or reduced synthesis of NO or other local factors. We think it will be possible in future studies, using a combination of OCT assessment and simultaneous microdialysis delivery of specific pathway antagonists, ${ }^{33-35}$ to pharmacodissect individual pathways responsible for the regulation of cutaneous microvascular dysfunction/ function in health and disease.

Reduced local heating responses in the skin of diabetic subjects have previously been observed using LDF. The maximum skin microvascular response to local heating was significantly impaired in type 1 diabetes mellitus (T1DM), ${ }^{36}$ type 2 diabetes mellitus (T2DM) ${ }^{26}{ }^{37}$ and T1DM/T2DM with neuropathy and ischemic neuropathy, ${ }^{38}$ compared with healthy controls. Unfortunately, this modality (and others such as LDI and $\mathrm{TcpO}_{2}$ monitor), along with local heating approaches, were unable to discriminate the severity of impairment in skin microvascular responses between diabetics with and without ulceration. ${ }^{37}$ Furthermore, none of these studies directly observed or quantified individual structural or functional changes in microvessel beds, which we were able to achieve using our OCT approach. Ours is therefore the first study, to our knowledge, to both visualize and quantify differences in diameter, speed, flow rate and density at rest and in response to physiological stimulation in diabetic and control subjects.

Our study has several limitations. Since skin microvascular density is heterogeneous, different vascular beds may exhibit distinct responses to the local heating. ${ }^{39}$ OCT imaging was obtained from a small area of skin microvessels and may not be a representative of other areas of the skin. This limitation is common to other techniques such as LDF, Near Infrared Spectroscopy (NIRS) and also to biopsy approaches. We also rendered the images in two dimensions. It is feasible that future development might enable 3D imaging. A further limitation is that our pilot study was performed in a limited sample of diabetic and control subjects. Future studies should be conducted to longitudinally assess larger cohorts of patients and to determine the utility of OCT in risk stratifying the diabetic foot, predicting outcomes and instituting early treatment. Finally, it is important to emphasize that the current OCT approach we use has poor temporal resolution and it is also impractical to use a $30 \mathrm{~min}$ heating protocol to assess microvascular structure and function in a working clinic. However, these issues will be overcome as OCT technology advances and it is highly feasible that more rapid heating protocols will be developed.

\section{CONCLUSIONS}

Our novel findings indicate that OCT may offer powerful insights into the pathology/physiology of microvascular diseases in humans. We have demonstrated the feasibility of directly visualizing changes in microvascular function and structure in healthy subjects and quantified abnormalities which are disease severity specific in patients with diabetes. The techniques we introduce in this study may prove useful for diagnosing early stages of microvascular 
disease in high-risk patients, in characterizing disease progression and assessing the efficacy of therapeutic interventions.

\section{Author affiliations}

${ }^{1}$ Physiology, Airlangga University Faculty of Medicine, Surabaya, Jawa Timur, Indonesia

${ }^{2}$ Cardiovascular Research Group, School of Human Sciences (Exercise and Sport Science), The University of Western Australia, Crawley, Western Australia, Australia ${ }^{3}$ Faculty of Health and Medical Sciences, Adelaide Medical School, Australian Research Council Centre of Excellence for Nanoscale Biophotonics, University of Adelaide, Adelaide, South Australia, Australia

${ }^{4}$ Institute for Photonics and Advanced Sensing, University of Adelaide, Adelaide, South Australia, Australia

${ }^{5}$ Faculty of Health and Medical Sciences, School of Surgery, The University of Western Australia, Perth, Western Australia, Australia

${ }^{6}$ School of Medicine and Pharmacology, The University of Western Australia, Perth, Western Australia, Australia

${ }^{7}$ Department of Endocrinology and Diabetes, Fiona Stanley Hospital, Perth, Western Australia, Australia

${ }^{8}$ Vascular and Endovascular Surgery, Sir Charles Gairdner Hospital, Perth, Western Australia, Australia

Contributors RA, SZJ, SJJ, RAM, LHN, BBY, and DJG conceived and designed the experiments. RA and SZJ collected the data. RA, RAM, and HHC analyzed the data. RA, DJG, and RAM wrote the manuscript with input from all authors. RA and DJG are the guarantors of this work and, as such, had full access to all the data in the study and take responsibility for the integrity of the data and the accuracy of the data analysis.

Funding RA is supported by a scholarship from Indonesian Endowment Fund for Education, Ministry of Finance, Indonesia. RAM is supported by a Premier's Research and Industry Fund grant provided by the South Australian Government Department for Industry and Skills. DJG is a National Health and Medical Research Council Principal Research Fellow. This research is supported by grants from Australia Research Council (DP 130103793, DP 160104175, CE140100003).

Competing interests RAM is a co-founder and director of Miniprobes, a company that develops novel optical imaging systems.

Patient consent for publication Not required.

Ethics approval The study was approved by Sir Charles Gairdner and Osborne Park Health Group Ethics Committees (project research number: RGS0000001881), with approval also granted by The University of Western Australia's Human Research Ethics Committee. The study conformed to the standards outlined in the Declaration of Helsinki. All participants provided written informed consent.

Provenance and peer review Not commissioned; externally peer reviewed.

Data availability statement All data relevant to the study are included in the article. Any information obtained from the participants was deidentified.

Open access This is an open access article distributed in accordance with the Creative Commons Attribution Non Commercial (CC BY-NC 4.0) license, which permits others to distribute, remix, adapt, build upon this work non-commercially, and license their derivative works on different terms, provided the original work is properly cited, appropriate credit is given, any changes made indicated, and the use is non-commercial. See: http://creativecommons.org/licenses/by-nc/4.0/.

ORCID IDs

Robert A McLaughlin http://orcid.org/0000-0001-6947-5061

Daniel J Green http://orcid.org/0000-0003-3226-2921

\section{REFERENCES}

1 Singh N, Armstrong DG, Lipsky BA. Preventing foot ulcers in patients with diabetes. JAMA 2005;293:217-28.

2 Zhang P, Lu J, Jing Y, et al. Global epidemiology of diabetic foot ulceration: a systematic review and meta-analysis ${ }^{\dagger}$. Ann Med 2017;49:106-16

3 Federation ID. Time to act: diabetes and foot care. IDF, 2005.

4 Gordois A, Scuffham P, Shearer A, et al. The health care costs of diabetic peripheral neuropathy in the US. Diabetes Care 2003;26:1790-5.
5 Hicks CW, Selvarajah S, Mathioudakis N, et al. Burden of Infected Diabetic Foot Ulcers on Hospital Admissions and Costs. Ann Vasc Surg 2016;33:149-58.

6 Boulton AJ. The pathogenesis of diabetic foot problems: an overview. Diabet Med 1996;13:S12-16.

7 Flynn MD, Tooke JE. Aetiology of diabetic foot ulceration: a role for the microcirculation? Diabet Med 1992;9:320-9.

8 Chao CYL, Cheing GLY. Microvascular dysfunction in diabetic foot disease and ulceration. Diabetes Metab Res Rev 2009;25:604-14.

9 Uccioli L, Mancini L, Giordano A, et al. Lower limb arterio-venous shunts, autonomic neuropathy and diabetic foot. Diabetes Res Clin Pract 1992;16:123-30.

10 Parving $\mathrm{HH}$, Viberti GC, Keen $\mathrm{H}$, et al. Hemodynamic factors in the genesis of diabetic microangiopathy. Metabolism 1983;32:943-9.

11 Sandeman DD, Shore AC, Tooke JE. Relation of skin capillary pressure in patients with insulin-dependent diabetes mellitus to complications and metabolic control. N Engl J Med 1992;327:760-4.

12 Tooke JE. Peripheral microvascular disease in diabetes. Diabetes Res Clin Pract 1996;30:S61-5.

13 Lowry D, Saeed M, Narendran P, et al. The difference between the healing and the nonhealing diabetic foot ulcer: a review of the role of the microcirculation. J Diabetes Sci Technol 2017;11:914-23.

14 Klingel R, Mumme C, Fassbender T, et al. Rheopheresis in patients with ischemic diabetic foot syndrome: results of an open label prospective pilot trial. Ther Apher Dial 2003;7:444-55.

15 McNeely MJ, Boyko EJ, Ahroni JH, et al. The independent contributions of diabetic neuropathy and vasculopathy in foot ulceration. How great are the risks? Diabetes Care 1995;18:216-9.

16 Yang $\mathrm{C}$, Weng $\mathrm{H}$, Chen L, et al. Transcutaneous oxygen pressure measurement in diabetic foot ulcers: mean values and cut-point for wound healing. J Wound Ostomy Continence Nurs 2013;40:585-9.

17 Lawson D, Petrofsky JS. A randomized control study on the effect of biphasic electrical stimulation in a warm room on skin blood flow and healing rates in chronic wounds of patients with and without diabetes. Med Sci Monit 2007;13:CR258-63.

18 Petrofsky JS, Lawson D, Berk L, et al. Enhanced healing of diabetic foot ulcers using local heat and electrical stimulation for 30 min three times per week. J Diabetes 2010;2:41-6.

19 Braverman IM. The cutaneous microcirculation. J Investig Dermatol Symp Proc 2000;5:3-9.

20 Smith KJ, Argarini R, Carter HH, et al. Novel noninvasive assessment of microvascular structure and function in humans. Med Sci Sports Exerc 2019;51:1558-65.

21 Argarini R, McLaughlin RA, Naylor LH, et al. Assessment of the human cutaneous microvasculature using optical coherence tomography: proving Harvey's proof. Microcirculation 2020;27:e12594.

22 Atkinson CL, Carter HH, Thijssen DHJ, et al. Localised cutaneous microvascular adaptation to exercise training in humans. Eur J Appl Physiol 2018;118:837-45.

23 Choi PJ, Brunt VE, Fujii N, et al. New approach to measure cutaneous microvascular function: an improved test of NO-mediated vasodilation by thermal hyperemia. J Appl Physiol 2014;117:277-83.

24 Gambichler T, Matip R, Moussa G, et al. In vivo data of epidermal thickness evaluated by optical coherence tomography: effects of age, gender, skin type, and anatomic site. J Dermatol Sci 2006;44:145-52.

25 Liew YM, McLaughlin RA, Gong P, et al. In vivo assessment of human burn scars through automated quantification of vascularity using optical coherence tomography. J Biomed Opt 2013;18:061213.

26 Sandeman DD, Pym CA, Green EM, et al. Microvascular vasodilatation in feet of newly diagnosed non-insulin dependent diabetic patients. BMJ 1991;302:1122-3.

27 Hozo SP, Djulbegovic B, Hozo I. Estimating the mean and variance from the median, range, and the size of a sample. BMC Med Res Methodol 2005;5:13

28 Sohn E, Suh BC, Wang N, et al. A novel method to quantify cutaneous vascular innervation. Muscle Nerve 2020. doi:10.1002/ mus.26889. [Epub ahead of print: 08 Apr 2020].

29 Adamska A, Pilacinski S, Zozulinska-Ziolkiewicz D, et al. An increased skin microvessel density is associated with neurovascular complications in type 1 diabetes mellitus. Diab Vasc Dis Res 2019;16:513-22

30 Johnson JM, Minson CT, Kellogg DL. Cutaneous vasodilator and vasoconstrictor mechanisms in temperature regulation. Compr Physiol 2014;4:33-89.

31 Minson CT, Berry LT, Joyner MJ. Nitric oxide and neurally mediated regulation of skin blood flow during local heating. J Appl Physiol 2001;91:1619-26. 
32 Kellogg DL, Liu Y, Kosiba IF, et al. Role of nitric oxide in the vascular effects of local warming of the skin in humans. J Appl Physiol 1999;86:1185-90.

33 Black MA, Green DJ, Cable NT. Exercise prevents age-related decline in nitric-oxide-mediated vasodilator function in cutaneous microvessels. J Physiol 2008;586:3511-24.

34 Naylor LH, Davis EA, Kalic RJ, et al. Exercise training improves vascular function in adolescents with type 2 diabetes. Physiol Rep 2016;4:e12713.

35 Naylor LH, Yusof NM, Paramalingam N, et al. Acute hyperglycaemia does not alter nitric oxide-mediated microvascular function in the skin of adolescents with type 1 diabetes. Eur J Appl Physiol 2014;114:435-41.
36 Rayman G, Williams SA, Spencer PD, et al. Impaired microvascular hyperaemic response to minor skin trauma in type I diabetes. $\mathrm{Br}$ Med J 1986;292:1295-8.

37 Krishnan STM, Baker NR, Carrington AL, et al. Comparative roles of microvascular and nerve function in foot ulceration in type 2 diabetes. Diabetes Care 2004;27:1343-8.

38 Veves A, Akbari CM, Primavera J, et al. Endothelial dysfunction and the expression of endothelial nitric oxide synthetase in diabetic neuropathy, vascular disease, and foot ulceration. Diabetes 1998;47:457-63.

39 Roustit M, Blaise S, Millet C, et al. Reproducibility and methodological issues of skin post-occlusive and thermal hyperemia assessed by single-point laser Doppler flowmetry. Microvasc Res 2010;79:102-8 